\title{
Controlled clinical trial of how mobile health applications affect blue-collar men's physical health as well as thoughts and actions in relation to their own physical health
}

\author{
Vinie Diana Hvidbak Levisen, Francisco Mansilla Castaño, Camilla Skovbjerg Jensen \\ University College South, Haderslev and Esbjerg, Haderslev, Denmark \\ Contributions: (I) Conception and design: VDH Levisen; (II) Administrative support: None; (III) Provision of study material or patients: VDH \\ Levisen; (IV) Collection and assembly of data: VDH levisen; (V) Data analyses and interpretation: All authors; (VI) Manuscript writing: All authors; \\ (VII) Final approval of manuscript: All authors. \\ Correspondence to: Vinie Diana Hvidbak Levisen. UC Syd Lembckeksvej 7, 6100 Haderslev, Denmark. Email: vdhl@ucsyd.dk.
}

Background: Blue collar men have both the lowest average life and longest patient delay, and currently
no research has been conducted with mobile health applications as health promotion interventions for this
target group. This study wants to contribute with knowledge about how mobile health applications affect
the level of physical activity amongst blue collar men as well as the frequency of how often they think and do
something for their own physical health.

Methods: Controlled clinical trial, men, aged 19-62 years, working in industrial companies, who are assigned to an intervention group $(n=35)$ or a control group $(n=35)$ are allocated based on mobile phone type/model. Baseline and effect measurement is carried out in both groups. Intervention period of 6 months in which the intervention group uses mobile applications that record the number of steps, and they receive a health-promoting text message every other week, and, every 4 weeks, the men send the recorded number of steps as well as visual analogue scale (VAS) thinking and doing in a selected week.

Results: During the intervention period, the following parameters have improved significantly in the intervention group: muscle mass, from 67.9 to $68.8 \mathrm{~kg}(\mathrm{P}=0.02)$; oxygen absorption in the fitness test, from 3.09 to $3.22 \mathrm{~L} / \mathrm{min}(\mathrm{P}=0.03)$; VAS, how often the men do something to improve their own physical health, from 6.00 to $7.00(\mathrm{P}=0.0051)$. There are improved parameters in the intervention group for resting heart rate (RHR), fitness test, fat percentage and VAS thinking. For blood pressure (BP), there is a surprising increase in the intervention group: systolic blood pressure (SBP) from 134 to $136 \mathrm{~mm} / \mathrm{Hg}(\mathrm{P}=0.09)$ and diastolic 83 to $86 \mathrm{~mm} / \mathrm{Hg}(\mathrm{P}=0.03)$.

Conclusions: The use of mobile health applications, health promoting text messages and step-bystep control increases the physical activity level of blue-collar men as well as how often they think and do something to improve their physical health. Significant improvement is seen in their muscle mass and oxygen uptake as well as in relation to how often they do something to improve their own health.

Keywords: Physical health; blue-collar men; mobile apps

Received: 31 August 2017; Accepted: 26 September 2017; Published: 19 October 2017.

doi: 10.21037/jhmhp.2017.09.01

View this article at: http://dx.doi.org/10.21037/jhmhp.2017.09.01

\section{Introduction}

It is well-known that men report illness and health problems less than women, despite the fact that men of all ages have a higher mortality rate than women. At the same time, men evaluate their own physical and mental health more positively than women $(1,2)$.

A high degree of social inequality is reflected in men's average lifespan when considering length of education and 
income group, and today the richest $25 \%$ of Danish men live on average 10 years longer than the poorest $(3,4)$. In the Nordic countries, men live on average 4 to 5 years less than women; therefore, it is relevant to focus on the health of men with little or no education and how their average lifespan can be increased $(2,5)$. Based on the WHO's definition, health is " $a$ state of complete physical, mental and social well-being and not only the absence of disease or infirmity" (6).

Men's lifestyles contribute to the increasing incidence of lifestyle-related illnesses and early death, including circulatory and endocrine illnesses, and statistically, men with little or no education have several risk factors, such as smoking, alcohol abuse and physical inactivity. Such lifestyles and risk factors means that today it is normal for Danish men to be overweight; $54.3 \%$ of men have a BMI of over 25 , compared to $40.7 \%$ of women (7-9).

In Denmark, it is estimated that inactivity results in 6,000 additional deaths annually, resulting in 14,000 years of lost life amongst men and 8,300 years of lost life amongst women. In addition, physical inactivity is related to 710,000 additional contacts (e.g., appointments, telephone calls) to a GP, 1.2 million extra days leave and almost 1,800 additional people granted early retirement every year. Annually, physical inactivity results in additional costs of DKK 5.3 billion for treatment and care, and additional costs of DKK 12 billion in loss of production $(7,10)$.

Another explanation for men's lower average life expectancy is a range of characteristics of men's health psychology; for example, men avoid dealing with issues concerning their own physical and mental conditions, including seeking help and making use of the healthcare system's offers. This can be seen by prolonged patient delay $(3,11,12)$.

According to several researchers, three main delay periods can be distinguished: patient delay, doctor delay and system delay (12). Research shows that the length of delay is influenced by the individual's socioeconomic status, where low income, little education, and living alone increase all three delays (12). Therefore, it is interesting whether mobile health applications can increase men's thoughts and actions about their own health and possibly reduce patient delay (13).

Evidence suggests that physical activity can increase well-being and is also positively associated with humour and mood level; therefore, this research project will focus on men's physical activity (13).

Mobile applications as interventions for increased physical activity show that, in a mixed audience in terms of gender, age and education, an increase of $800-1,104$ steps per day can be expected with an intervention period from 2 weeks to 6 months-most being in 2 to 8 weeks (14-17). However, current research has not investigated the effect amongst blue-collar men. Here, blue-collar men are understood as workers who perform manual labour (18-20).

A study on health-promoting interventions shows that men want to participate in health-promoting and preventive interventions if the interventions are located where they already are (10). Several studies indicate the workplace as an appropriate intervention arena $(3,10)$, and therefore, the trial was carried out at three Danish industrial companies.

The selection of the mobile health application is based on research on what an application should contain in order to increase the probability of an effect. The selection criteria are that it should be simple, free, always active, record the number of steps and allow other physical activity to be registered, and measured in minutes. In addition, it should be possible to read the number of steps and the minutes for the previous 4 weeks. With these criteria, the "Google Fit" app was chosen for Android mobile phones and the "Health" app was chosen for iPhones-both made it possible for the participant to formulate personal goals for their physical activity and receive a motivational feedback message when they had reached their goal (21-23).

\section{Purpose and research questions}

The purpose of the trial was to contribute knowledge about how mobile health applications influence the physical activity level of men with little or no education as well as the frequency of how often they think and do something for their own physical health. The results and knowledge from the trial could be used by the workplaces, healthcare system and politicians, and since the intervention does not require professional contact, it is also cost-effective.

The preliminary literature search in relation to the current knowledge of men's health, mobile applications and physical activity has limited the trial to the following research areas:

(I) To investigate what impact mobile health applications have on blue-collar men's thoughts and actions regarding their own physical health;

(II) To investigate how mobile health applications influence blue-collar men's level of physical activity;

(III) To investigate the effect of mobile health applications on blue-collar men's fitness, resting heart rate (RHR), resting blood pressure (BP), distribution of body and muscle mass. 
How often are you thinking about your physical health?

How often are you doing something to improve your physical health?

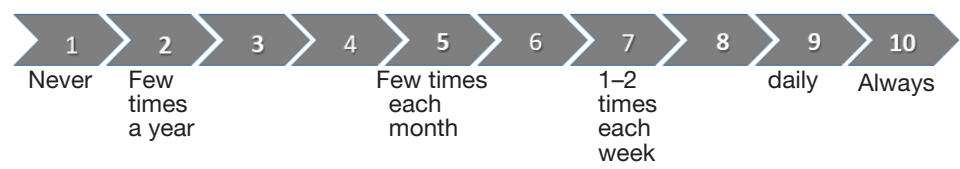

Figure 1 The VAS for thinking and doing. VAS, visual analogue scale.

\section{Methods}

\section{Study population and selection criteria}

A controlled clinical trial is used to gain knowledge about the effect of mobile health applications on improving the men's physical activity as well as the frequency of them thinking and doing something to improve their physical activity. Since the men's type of mobile phone was used to place participants in the control group or the intervention group, it is not possible to allocate the participants randomly. Participants with either an Android phone that can use the application "Google Fit" or with an iPhone that can use the "Health" application were assigned to the intervention group; participants with phones that could not use the selected applications were allocated to the control group.

The control group ( $\mathrm{n}=35)$ and intervention group $(\mathrm{n}=35)$ consist of men aged 19 to 62 years old with little or no education who are employed at major Danish industrial companies. The men in the intervention group must have an Android smartphone or an iPhone that can use either the "Google Fit" or "Health" application and read Danish text messages.

\section{Intervention}

The intervention was carried out in the period September 2015 to March 2016 and included:

(I) Use of the "Google Fit" or "Health" application;

(II) A text message with a general health-promoting message every other week. This message has been developed with a focus on a low readability index as well as a focus on actions rather than feelings $(3,11)$;

(III) Checking of the number of steps and reporting visual analogue scale (VAS) scores every 4 weeks.

\section{Measurements procedure}

Seven measurements were carried out over the intervention period, where the first is the baseline and the last is the effect measurement. Baseline and effect measurements were carried out at the participants' workplaces during work hours and included:

Standardized electronic measurement of systolic blood pressure (SBP), diastolic blood pressure (DBP) and RHR (24) (apparatus: Microlife BPA100 Plus);

VAS scores for how often the participant thinks about his own physical health by stating a number between 1-10, graded from "never" to "always" (see Figure 1);

VAS scores for how often the participant does something for his own physical health by stating a number between 1-10, graded from "never" to "always" (see Figure 1);

Measuring of fitness rating via computer-controlled step test;

Measuring of body mass index, oxygen uptake and distribution of muscle mass (apparatus: TANITA Body Composition Analyzer BC-420MA).

The baseline for the number of steps amongst the intervention group is the first intervention week.

At baseline, the intervention group receives the VAS (see Figure 1) so that each intervention measurement can assess which number describes their actions and thoughts about their own physical health. At baseline, the intervention group is also given written instructions regarding downloading and using the chosen mobile health application.

The longitudinal measurements were carried out every 4th week and included:

(I) Self-reported number of steps in a chosen week. The specific week is chosen by the researcher and is not known by the men before they receive the text message about which week they have to report data from;

(II) VAS scores of how often the participant thinks about his own physical health by stating a number between 1-10, graded from "never" to "always" (see Figure 1);

(III) VAS scores of how often the participant does something for his own health by stating a number between 1-10, graded from "never" to "always" (see Figure 1). 


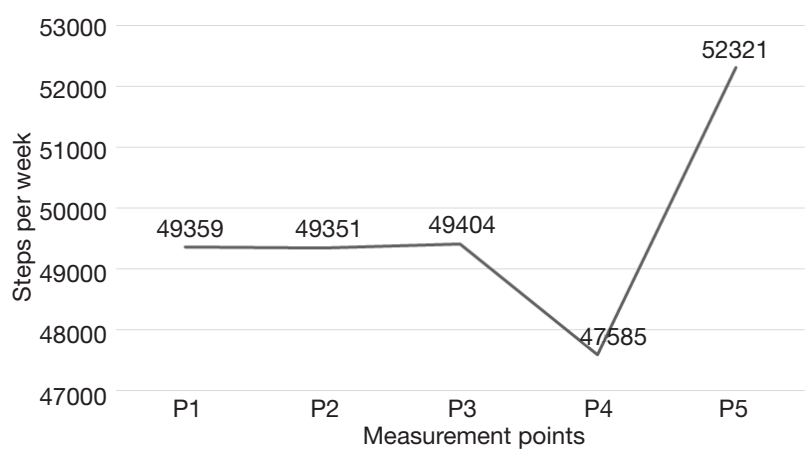

Figure 2 Average number of steps per week from measurement one to five.

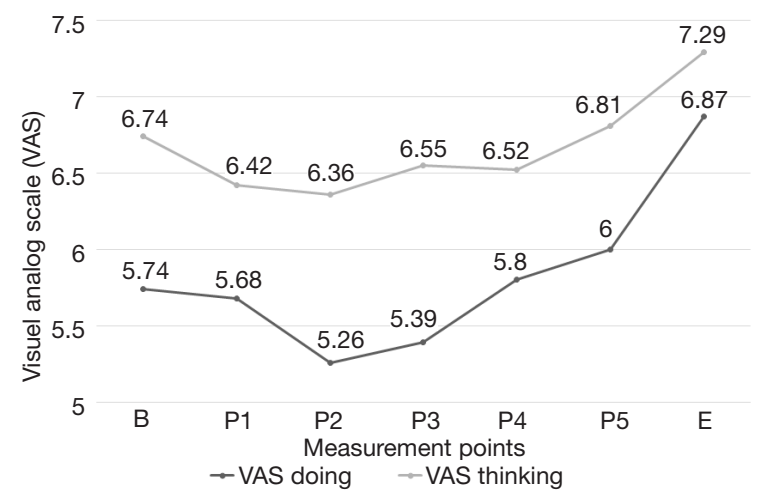

Figure 3 Effect of intervention on VAS doing and VAS thinking. VAS, visual analogue scale.

The initial baseline and the effect measurement after 6 months was planned to make it possible to compare the results between the intervention and control group. At the same time, longitudinal measurements are conducted every 4th week in the intervention group to provide knowledge about the effect of mobile health applications over time. The men sent the longitudinal measurements to the researchers via text message.

To gain an insight into how the individual intervention elements (the intervention group) as well as the actual baseline and effect measurements (the intervention and control group) have influenced the men's thoughts and actions in relation to their own physical health, both the intervention and control group answered an online questionnaire in SurveyXact immediately after the effect measurement.

The control group's questionnaire contained questions related to the baseline and effect measurement, since they did not participate in other intervention elements. The intervention group's questionnaire contained questions related to all the intervention elements as well as the baseline and effect measurement.

\section{Statistical analysis}

The statistical analysis was performed in SPSS (version 22, IBM software), and the significance level set to $5 \%$. The statistical work is recorded in an associated logbook.

Descriptive statistics are used to characterize the intervention and control group with regard to the registered baseline characteristics. Continuous variables are described by mean values or medians, depending on the distribution of data.

One-way repeated measures ANOVA was performed in order to investigate whether a change occurs amongst the men in the intervention group in relation to how often they think about their own health and how often they do something to improve their own health. This was done by comparing seven independent VAS measurements from the entire intervention period. VAS thinking uses the Greenhouse-Geisser correction with degrees of freedom of 3.79 in numerator and 113.81 in denominator, with a significance of 0.025 and dos not assume sphericity. VAS doing uses the Greenhouse-Geisser correction with degrees of freedom of 3.77 in numerator and 113.23 in denominator, with a significance of 0.001 and does not assume sphericity. A pairwise comparison was also carried out.

Five independent measurements were also examined via one-way repeated measures ANOVA about whether a change occurred in the men's physical activity level (number of steps) over the intervention period.

The final effect of the intervention was investigated by comparing the intervention and control group, where normal distributed data was compared using a $t$-test and non-normalized data via the Wilcoxon test.

The question of whether the men's fitness, oxygen uptake, body mass index, muscle mass, BP and heart rate changed during the intervention period was also investigated. For this, a paired $t$-test or Wilcoxon test was used to compare baseline data and data at the effect measurement.

\section{Results}

\section{Population study}

All participants in the control group took part in both the 
Table 1 Measurement of VAS thinking and doing, physical- and cardiovascular parameters at baseline and effect measurement

\begin{tabular}{|c|c|c|c|c|c|c|}
\hline Variable & \multicolumn{3}{|c|}{ Control group $(\mathrm{n}=35)$} & \multicolumn{3}{|c|}{ Intervention group $(n=33)$} \\
\hline VAS thinking (NND) & 7.00 & 7.00 & 0.87 & 7.00 & 8.00 & 0.11 \\
\hline VAS doing (NND) & 7.00 & 7.00 & 0.76 & 6.00 & 7.00 & $5.10^{-3 x}$ \\
\hline Fitness rating $(\mathrm{mL} / \mathrm{min} / \mathrm{kg})(\mathrm{ND})$ & 33.00 & 33.66 & 0.39 & 36.03 & 37.18 & 0.07 \\
\hline Muscle mass (kg) (ND) & 67.80 & 67.30 & 0.46 & 67.80 & 68.89 & $0.02^{*}$ \\
\hline Body fat (\%) (NND) & 14.90 & 19.10 & $0.02^{*}$ & 17.46 & 16.43 & 0.06 \\
\hline SBP (mmHg) (NND) & 142.94 & 139.00 & 0.13 & 134.00 & 136.00 & 0.09 \\
\hline DBP (mmHg) (NND) & 90.00 & 88.00 & 0.56 & 82.00 & 86.00 & $0.01^{*}$ \\
\hline
\end{tabular}

*, statistically significant $\mathrm{P}<0.05$. ND, normal distribution, average value and $t$-test; NND, non-normal distribution, median value and Wilcoxon test; VAS, visual analogue scale.

baseline and effect measurement. In the intervention group, of the 35 participants, two left the project after 2 months due to finding new employment; therefore, they are not included in the results.

Allocating participants to the control and intervention group based on their mobile phone caused a difference in the average ages of the two groups. The control group has an average age of 46 years, whereas the intervention group has an average age of 39 years.

\section{Longitudinal measurements in the intervention group, steps, VAS thinking and VAS doing}

Over the 6 months of the intervention period, participants in the intervention group sent text messages of the number of steps in 5 chosen weeks. At the first, second, and third measurement, the men maintained almost the same average number of steps per day. One-way ANOVA was carried out with 28 men. Five men were excluded because they had not reported one or more measurements due to telephone or application issues. One-way ANOVA with repeated measures did not show any significance between the five measurements. However, there is a difference between the first three measurements and measurement four with an average decrease of 1,819 steps per week. There is a marked increase between measurement 4 and 5 of 4,736 steps per week. There is an increase of 2,961 steps per week, on average, from measurement one to five, which is not significant (see Figure 2).
Over the 6 months of the intervention period, participants in the intervention group sent text messages with VAS scores for thinking and doing for five selected dates' to the project manager, which were also measured at baseline (B) and the effect measurement (E). These seven independent measurements of VAS thinking and doing were carried out by 31 men from the intervention group. Two men were excluded because they had not reported one or more measurements due to telephone issues.

One-way repeated measures ANOVA of VAS thinking shows no significance. In a pairwise comparison, there is a significant difference between effect measurement $(\mathrm{E})$ and $\mathrm{P} 1(\mathrm{P}=0.005), \mathrm{P} 2(\mathrm{P}=0.06), \mathrm{P} 3(\mathrm{P}=0.013), \mathrm{P} 4(\mathrm{P}=0.09)$ and $\mathrm{P} 5(\mathrm{P}=0.03)$ (see Figure 3).

One-way repeated measures ANOVA of VAS doing shows a significant linearity $(\mathrm{P}=0.003)$, which is a particularly noticeable from measurement three (P3) to effect measurement (E) (see Figure 3). A pairwise comparison shows that effect measurements are significantly different from all the other measurements $\mathrm{B}(\mathrm{P}=0.004), \mathrm{P} 1(\mathrm{P}=0.001)$, $\mathrm{P} 2(\mathrm{P}<0.001), \mathrm{P} 3(\mathrm{P}<0.001), \mathrm{P} 4(\mathrm{P}=0.03)$ and $\mathrm{P} 5(\mathrm{P}=0.017)$. There is also a significant difference between $\mathrm{P} 1$ and $\mathrm{P} 2$ measurements $(\mathrm{P}=0.025)$ and $\mathrm{P} 2$ and $\mathrm{P} 5$ measurements $(\mathrm{P}=0.023)$.

Figure 3 shows the average values of the seven measurements for VAS thinking and VAS doing. The two graphs show a decrease from the measurements at B to P2, after which both graphs increase to the effect measurement. 
Table 2 The intervention elements' influence on VAS thinking and VAS doing

\begin{tabular}{|c|c|c|c|c|c|c|c|c|}
\hline \multirow{3}{*}{ Variable } & \multicolumn{4}{|c|}{ Control group $(n=35)$, influence } & \multicolumn{4}{|c|}{ Intervention group ( $n=33)$, influence } \\
\hline & \multicolumn{2}{|c|}{ Thinking } & \multicolumn{2}{|c|}{ Doing } & \multicolumn{2}{|c|}{ Thinking } & \multicolumn{2}{|c|}{ Doing } \\
\hline & $\begin{array}{l}\text { Nothing- } \\
\text { little }\end{array}$ & $\begin{array}{l}\text { Something- } \\
\text { much }\end{array}$ & Nothing-little & Something-much & Nothing-little & $\begin{array}{l}\text { Something- } \\
\text { much }\end{array}$ & Nothing-little & $\begin{array}{c}\text { Something- } \\
\text { much }\end{array}$ \\
\hline Baseline & $42 \%$ & $58 \%$ & $39 \%$ & $61 \%$ & $9 \%$ & $91 \%$ & $21 \%$ & $79 \%$ \\
\hline Effect & $42 \%$ & $58 \%$ & $54 \%$ & $45 \%$ & $9 \%$ & $91 \%$ & $30 \%$ & $70 \%$ \\
\hline $\begin{array}{l}\text { Health- } \\
\text { promoting text } \\
\text { message }\end{array}$ & & & & & $27 \%$ & $73 \%$ & $27 \%$ & $73 \%$ \\
\hline $\begin{array}{l}\text { Number of } \\
\text { steps }\end{array}$ & & & & & $9 \%$ & $91 \%$ & $33 \%$ & $67 \%$ \\
\hline
\end{tabular}

\section{Baseline and effect points of VAS and physical bealth}

Table 1 shows that the men in the control group have the same median VAS value at baseline and effect measurement for both thinking and doing.

The median VAS value of doing at baseline is lower in the intervention group (6.00) than in the control group (7.00). The effect measurement shows that the control group's VAS thinking and doing is the same as at baseline, whereas the intervention group's VAS thinking and doing increased by +1 .

Several parameters show a significant improvement in the physical health of the men in the intervention group when the measurements at baseline are compared with the effect measurements.

The intervention group has improved their distribution of fat with a decrease of $1.03 \%$, increased their fitness rating and showed a significant increase in both muscle mass of $1.09 \mathrm{~kg}(\mathrm{P}=0.02)$ and oxygen uptake of $0.13 \mathrm{~L} / \mathrm{min}(\mathrm{P}=0.03)$ (see Table 1).

Over the intervention period, the control group had a significant average increase in the distribution of fat and muscle mass. The fat percentage increased significantly, by $4.2 \%(\mathrm{P}=0.02)$, and they have a small decrease in muscle mass of $0.5 \mathrm{~kg}$. The control group's fitness rating and oxygen uptake also made a small improvement (see Table 1).

In relation to the cardiovascular, a slight decrease can be seen in the control group's SBP and DBP between baseline measurement and the effect measurement, whereas the intervention group's SBP and DBP is higher at the effect measurement and DBP is significantly higher $(\mathrm{P}=0.01)$ (see Table 1). The results from the effect measurement show a decrease in the intervention group's RHR, whereas there is a slight increase in the control group's RHR. The intervention group's decrease in RHR is consistent with their improved fitness rating and $\mathrm{VO}_{2}$ capacity (Table 1).

\section{The importance of intervention elements}

The results from SurveyXact show that completing the various tests at baseline and the effect measurement has affected $91 \%$ of the intervention group's thinking (something-much), whereas it has only affected $58 \%$ of the control group's thinking (something-much). Participation at baseline and the effect measurement has affected the intervention group and the control group's doing less than their thinking. However, it is clear that it has affected the intervention group's thinking more than the control group. For both groups, it also shows that baseline affects doing more than the effect measurement.

The intervention elements that primarily (91\%) affect the intervention group's thinking (something-much) are the sending of a selected week's number of steps and participation at baseline and effect measurement.

The intervention elements that primarily affect the intervention group's doing are the baseline measurement (with $79 \%$ ) as well as the health-promoting text message every other week (with $73 \%$ ) (see Table 2).

\section{Discussion}

This controlled clinical trial shows that the use of mobile 
health applications affects the physical health of bluecollar men's physical health, with improvements in their fitness, RHR, fat percentage and a significant improvement in their muscle mass and oxygen absorption. A review of qualitative and randomized controlled trial studies of the impact of mobile health applications on physical activity (25) also shows that mobile applications can promote physical activity, albeit with moderate results in terms of an increase in the number of steps and BMI. Based on the results of the trial, the use of BMI as an indicator of the effect of physical activity can be discussed; the trial shows an increase in muscle mass and a decrease in fat, which means that a change in BMI may not be apparent, even though the men are physically healthier. Somewhat surprisingly, DBP and SBP increased in the intervention group, where a large cohort study shows a correlation between physical activity, such as daily walks, and decreasing BP (19). The measured $\mathrm{BP}$ at the effect measurement can presumably also be a sign that the participants in the intervention group were more interested in their physical measurements than the participants in the control group, which was also indicated by the improved fitness rating, $\mathrm{VO}_{2}$ and decreasing RHR in the intervention group.

The first measurement of steps (P1) (see Figure 2) is the first intervention week, which serves as the baseline measurement. Even though the men were informed that they should walk as they normally did this week, the measurement will presumably be higher than normal, both due to the influence of the application as well as that the men had just completed the physical measurements at baseline, and it is the baseline measurement that primarily affects men's thoughts and actions in relation to their own physical health (see Table 2). This decrease of 1,819 steps per week from the $3 \mathrm{rd}$ to the 4th measurement cannot be immediately explained based on the time of measurement (e.g., due to holiday), but it can be a sign that the application's influence on the men's thoughts and actions is decreasing. The large increase of 4,736 steps per week that is recorded from the fourth to the fifth measurement can, amongst other things, be a sign that the forthcoming effect measurement affected their thoughts and actions, which is confirmed by an increasing curve of VAS thinking and VAS doing from P5 to the effect measurement in Figure 3 (14-16,25). The registering of steps every 4th week is self-registered, but the effect measurement shows physical improvements corresponding to the intervention group having had an increased activity level, and thus it is presumed that there is a low information bias.
Figure 3 and Table 2 show that intervention, baseline and the effect measurement have influenced the frequency of how often the men think and do something to promote their own physical health. The longitudinal measurements of VAS thinking and doing show that the men thought about their physical health at the baseline measurement more often than they do something. This difference is reduced at the effect measurement, indicating a better correlation between the frequency of thinking and doing something to promote one's own personal physical health. In future studies, it could be interesting to investigate whether this balance between VAS thinking and doing can reduce these men's patient's delay so that they do not only think about going to, for example, the doctor, but that they actually do it (26).

There is an indication that the time of year for completing the intervention is significant. The results in the control group show that in the fall and winter period (September-March) the men increased their fat percentage from $14.90 \%$ to $19.10 \%$, on average, and their muscle mass decreased by an average of 500 grams. At the completion of the initial physical test, the men also expressed that they go into "hibernation" during the autumn and winter period. This may be something to be aware of for future studies.

The strengths of this trial are the high completion rate and number of participants in both the intervention and control groups, as well as the long intervention period of 6 months $(15,17)$. The limitations of the trial are that the participants could not be randomized, which has also led to an uneven distribution in terms of age between the control and intervention groups. It should be noted that the trial does not provide any knowledge of what the men are actually thinking with regard to their physical health; an issue that could be worthwhile investigating in future studies. It is not known whether the positive results will be maintained over time; however, it would be interesting to carry out a follow-up measurement after 6 and 12 months to investigate the effect without intervention. It is also not known whether a competitive element between men at the workplaces affected the results (27).

With regard to selection bias, a number of workers chose not to participate in the trial, and so the trial does not provide the complete picture of blue-collar men at the workplaces.

Following these positive results in influencing bluecollar men's thoughts and actions with regard to their physical health, it could be worthwhile investigating the same target group, but who are unemployed, since research 
shows that the unemployed are physically less active and assess their health-related quality of life to be worse $(28,29)$. Recent studies also show that patient delay amongst men is extended in relation to mental symptoms and diseases (30); therefore, it may be interesting to investigate whether mobile applications can also be used to affect men's thoughts and actions in terms of promoting mental health.

\section{Conclusions}

Based on the questionnaire (Table 2), mobile health applications (Google Fit and Health) affect blue-collar men's thoughts about their physical health more than they affect their actions. Of the intervention elements, it is the physical test at baseline and the health-promoting text message that primarily affect blue-collar men's actions with regard to promoting their physical health.

In the intervention group, there is a significant effect in the measurements of the men's muscle mass and oxygen uptake. In addition, there is an improvement in the intervention group's average RHR, fat percentage and fitness rating. In contrast, BP increased slightly. This effect should be seen in relation to the fact that the men in the control group showed a tendency to go into "hibernation" over the winter, with the result being that their muscle mass is reduced by an average of 500 grams and their fat percentage increased by $4.2 \%$.

\section{Acknowledgments}

The authors thank the three companies and the men employed by BILA, AKEA and Randers gear A/S for their participation in this study.

\section{Footnote}

Conflicts of Interest: All authors have completed the ICMJE uniform disclosure form (available at http://dx.doi. org/10.21037/jhmhp.2017.09.01). The authors have no conflicts of interest to declare.

Etbical Statement: The authors are accountable for all aspects of the work in ensuring that questions related to the accuracy or integrity of any part of the work are appropriately investigated and resolved. The study was conducted in accordance with the Declaration of Helsinki (as revised in 2013). Informed consent was waived due to the nature of the study. This research is reported and approved by the Data Inspectorate for Personal Data Protection Act $\$$ 48.1 complying with the current laws of Denmark.

Open Access Statement: This is an Open Access article distributed in accordance with the Creative Commons Attribution-NonCommercial-NoDerivs 4.0 International License (CC BY-NC-ND 4.0), which permits the noncommercial replication and distribution of the article with the strict proviso that no changes or edits are made and the original work is properly cited (including links to both the formal publication through the relevant DOI and the license). See: https://creativecommons.org/licenses/by-nc-nd/4.0/.

\section{References}

1. Danmarks statistik. Middellevetid for 0- årige i DK. Danmarks statistik. Available online: http://www.dst.dk/da/ Statistik/emner/doedsfald-og-middellevetid/middellevetid

2. Sundhedsstyrelsen. Men's health: a health status of men in Denmark and a review of effective interventions for promoting men's health - short version. Kbh, 2011. Available online: http://www.sst.dk/ /media/DBB49B5299 F54674AFB3D737CF623691.ashx

3. Madsen SA. Mænds sundhed og sygdomme. Frederiksberg: Samfundslitteratur; 2014.

4. Davidsen M. Dødelighed blandt socialt udsatte i Danmark 2007-2012: overdødelighed, middellevetid og dødsårsager. Odense; Kbh.: Statens Institut for Folkesundhed ; Rådet for Socialt Udsatte; 2013. Available online: http://www. si-folkesundhed.dk/upload/doedelighed-blandt-socialtudsatte-2007-2012_001.pdf

5. Norden Statbank. Middellevetid nordiske lande. Available online: http://norden.statbank.dk/LIFE02

6. WHO definition of Health. In: WHO definition of Health. New York: World Health Organization, 1948.

7. Eriksen L, Davidsen M, Jensen H, et al. Sygdomsbyrden i Danmark - risikofaktorer. Institut for Folkesundhed, SDU for SST; 2016. Available online: https://www.sst.dk/da/ sygdom-og-behandling/ /media/C3ACA2467BEE41B497 26532872563FFA.ashx

8. Hallman DM, Mathiassen SE, Gupta N, et al. A. Differences between work and leisure in temporal patterns of objectively measured physical activity among blue-collar workers. BMC Public Health 2015;15. Available online: http://www.biomedcentral.com/1471-2458/15/976

9. Jansbøl K, Rahbek AE. Sund Mand - litteraturstudiet. KORA; 2013. Available online: http://www.kora.dk/ media/763560/sund-mand---litteraturstudiet.pdf 
10. Kjøller M, Sundhedsstyrelsen. Mænds sundhed : en oversigt over mænds sundhedstilstand og en gennemgang af effektive forebyggelsesmetoder. Kbh.: SST; 2010. Available online: https://www.sst.dk/ /media/8B5495F18C 3942CDA9CF6C9A385E8819.ashx

11. Sjørup Simonsen S. Mænd, sundhed og sygdom ronkedorfænomenet. Århus: Klim; 2006.

12. Hansen RP, Olesen F, Sørensen HT, et al. Socioeconomic patient characteristics predict delay in cancer diagnosis: a Danish cohort study. BMC Health Serv Res 2008;8:49.

13. Buchholz SW, Wilbur J, Ingram D, et al. Physical activity text messaging interventions in adults: a systematic review. Worldviews Evid Based Nurs 2013;10:163-73.

14. Fanning J, Mullen SP, McAuley E. Increasing Physical Activity With Mobile Devices: A Meta-Analysis. J Med Internet Res 2012;14:e161.

15. Bort-Roig J, Gilson ND, Puig-Ribera A, et al. Measuring and Influencing Physical Activity with Smartphone Technology: A Systematic Review. Sports Med 2014;44:671-86.

16. Duncan M, Vandelanotte C, Kolt GS, et al. Effectiveness of a Web- and mobile phone-based intervention to promote physical activity and healthy eating in middleaged males: Randomized controlled trial of the ManUp study. J Med Internet Res 2014;16:e136.

17. Glynn LG, Hayes PS, Casey M, et al. Effectiveness of a smartphone application to promote physical activity in primary care: The smart move randomised controlled trial. Br J Gen Pract 2014;64:e384-91.

18. Muntaner A, Vidal-Conti J, Palou P. Increasing physical activity through mobile device interventions: A systematic review. Health Informatics J 2016;22:451-69.

19. Brouard B, Chieh A, Lelong H, et al. Study of a large cohort of connected devices users to assess the association between walking and blood pressure. J Hypertens 2015;33:e47.

20. Stephens J, Allen J. Mobile phone interventions to increase physical activity and reduce weight: A systematic review. J Cardiovasc Nurs 2013;28:320-9.

doi: 10.21037/jhmhp.2017.09.01

Cite this article as: Levisen VD, Castaño FM, Jensen CS. Controlled clinical trial of how mobile health applications affect blue-collar men's physical health as well as thoughts and actions in relation to their own physical health. J Hosp Manag Health Policy 2017;1:3.
21. Conroy DE, Yang CH, Maher JP. Behavior Change Techniques in Top-Ranked Mobile Apps for Physical Activity. Am J Prev Med 2014;46:649-52.

22. Tang J, Abraham C, Stamp E, et al. How can weight-loss app designers' best engage and support users? A qualitative investigation. Br J Health Psychol 2015;20:151-71.

23. Middelweerd A, van der Laan DM, van Stralen MM, et al. What features do Dutch university students prefer in a smartphone application for promotion of physical activity? A qualitative approach. Int J Behav Nutr Phys Act 2015;12:31.

24. Licht, Peter. Blodtryksmåling. Det Sundhedsvidenskablige Fakultet, SDU. 2010.

25. Coughlin SS, Whitehead M, Sheats JQ, et al. A Review of Smartphone Applications for Promoting Physical Activity. Jacobs J Community Med 2016;2. pii: 021.

26. Ilja Sabaj-Kjær, Svend Aage. Madsen. Manden og Lægen En interviewundersøgelse ved Forum for Mænds Sundhed blandt mænd, der ikke så tit bruger sundhedsvæsnet 2016. Available online: http://www.sundmand.dk/Manden_og_ laegen_Us.pdf

27. Engineering in Medicine and Biology Society. 2013 35th annual international conference of the IEEE Engineering in Medicine and Biology Society (EMBC 2013). Osaka, Japan: Institute of Electrical and Electronics Engineers (IEEE), 2013.

28. Illemann Christensen A, Folker AP. Mental sundhed blandt voksne danskere: analyser baseret på Sundhedsog sygelighedsundersøgelsen 2005. Kbh.; SST. 2010. Available online: http://www.sst.dk/ /media/F383B2EE7E 7848838A5A3E3FB06C008A.ashx

29. Smith L von H, Kristensen T. Fysisk aktivitet. SST. 2013. Available online: https://www.sst.dk/ /media/6B3A4AE69 8BC42139572C76C5854BA76.ashx

30. Madsen SA. Mænd og psykiske problemer En interviewundersøgelse ved Forum for Mænds Sundhed blandt mænd, der ikke så tit bruger sundhedsvæsnet. 2016; Available online: http://www.sundmand.dk/ M\%C3\%A6nd\%20og\%20psykiske\%20problemer.pdf 